\title{
Evidence-Based Clinical Practice Points for the Management of Venous Ulcers
}

\author{
Ravul Jindal $^{1}$ - D. B. Dekiwadia ${ }^{2} \cdot$ Pinjala Rama Krishna $^{3}$ - Ajay K. Khanna ${ }^{4} \cdot$ Malay D. Patel $^{5} \cdot$ Shoaib Padaria $^{6}$. \\ Roy Varghese ${ }^{7}$
}

Received: 8 November 2017 / Accepted: 15 January 2018 / Published online: 27 January 2018

(C) Association of Surgeons of India 2018

\begin{abstract}
Venous ulcer is an extremely common aetiology of lower extremity ulceration, which affects approximately $1 \%$ population in most of the countries, and the incidence rate increases with age and female gender. Proper assessment and diagnosis of both the patient and ulcer are inevitable in order to differentiate venous ulcers from other lower extremity ulceration and to frame an adequate and individualised management plan. Venous ulcers generally persist for weeks to many years and are typically recurrent in nature. This consensus aims to present an evidence-based management approach for the patients with venous ulcers. Various management options for venous ulcers include compression therapy, minimally invasive procedures like sclerotherapy and ablation techniques, surgical procedures, debridement and medical management with micronised purified flavonoid fraction (MPFF). Compression therapy is the mainstay treatment for venous ulcer. However, in failure cases, surgery can be preferred. Medical management with MPFF as an adjuvant therapy to standard treatment has been reported to be effective and safe in patients with venous ulcer. In addition to standard therapy, diet and lifestyle modification including progressive resistance exercise, patient education, leg elevation, weight reduction, maintaining a healthy cardiac status and strong psychosocial support reduces the risk of recurrence and improves the quality of life in patients with venous ulcer.
\end{abstract}

Keywords Venous ulcer $\cdot$ Compression $\cdot$ MPFF $\cdot$ Surgical procedures $\cdot$ Lifestyle modification

Electronic supplementary material The online version of this article (https://doi.org/10.1007/s12262-018-1726-3) contains supplementary material, which is available to authorized users.

Ravul Jindal

ravuljindalvul@gmail.com

1 Fortis Hospital, Mohali, Punjab, India

2 Dekiwadia Hospital, Rajkot, Gujarat, India

3 NIZAMS Institute of Medical Sciences, Hyderabad, Telangana, India

4 Institute of Medical Sciences, Banaras Hindu University, Varanasi, India

5 Apollo Hospital, Ahmedabad, India

6 Jaslok Hospital, Breach Candy Hospital, Sir H.N. Hospital, Saifee Hospital, Mumbai, India

7 Daya Hospital, Jubilee Mission Medical College, Trichur, Kerala, India

\section{Introduction}

Venous ulcers of the lower limbs, identified as stasis ulcers, or stasis dermatitis, or venous leg ulcer or varicose ulcers, are the most severe and devastating form of chronic venous insufficiency/disease (CVD) and accounts $\approx 80 \%$ of lower extremity ulcerations [1]. The prevalence of venous leg ulcers is stable between different countries and estimated to be $1 \%$ in most populations. Their incidence increases with age and female sex [2-4]. A large Indian study revealed that CVD is more prevalent at an average age of 43 years and it affects women more than men [5, $6]$.

Elevated venous pressure, turbulent flow and insufficient venous return due to venous occlusion or venous reflux are the proposed aetiologies, which activate inflammatory processes, triggering leukocyte activation, endothelial damage, platelet aggregation and intracellular oedema (Fig. 1) [1]. Older age, obesity, previous leg injuries, deep venous thrombosis and phlebitis are the various risk factors aggravating this complication (Fig. 2) [1]. Venous ulcers are 
Fig. 1 Diagrammatic representation of pathophysiology of venous ulcers

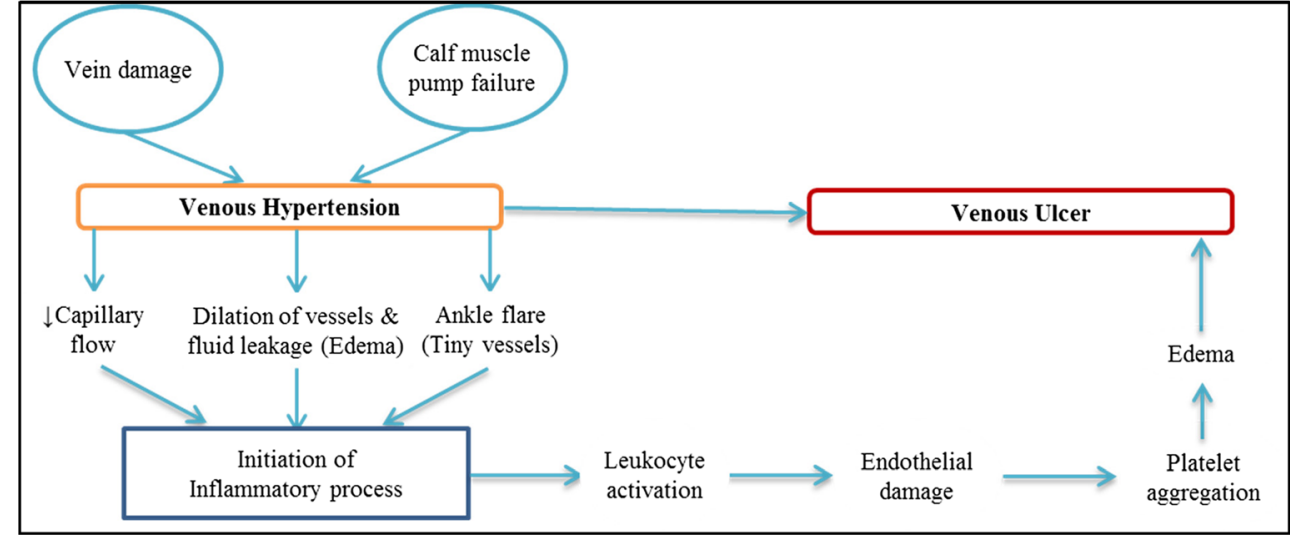

often recurrent and may continue from few weeks to few years and in some cases may lead to severe complications like malignancy. Though it has lower prevalence, the refractory nature of this disease has an expanded risk of morbidity, mortality and a significant impact on quality of life posing a great economic burden in India [7, 8].

Proper assessment of the extent of venous ulcers in India presents a significant challenge due to the absence of a central trauma/wound registry and quality research. Moreover, poor infrastructure, superstitions and beliefs of the rural population constrain proper management [9]. Several indigenous and traditional home remedies including honey, neem oil, Aloe vera and potato peels are regularly used by the Indian patients despite the lack of evidence advocating their use [10]. This consensus aims to present an evidence-based management approach for the patients with venous ulcers.

\section{Methodology}

This practice guideline for the management of venous ulcer, framed by The Association of Colon \& Rectal Surgeons of India (ACRSI), has been developed by experts from across the country with immense experience in managing patients with venous ulcer. The practice points presented in this document have been graded according to the European Society of Cardiology (ESC) grading system [11].

\section{Assessment and Diagnosis}

Effective management of venous ulcers depends on proper assessment and diagnosis, which includes examination of both ulcer and patient. Other lower limb ulcerations such as arterial insufficiency, prolonged pressure, diabetic neuropathy and
Fig. 2 Causes, risk factors, and signs and symptoms of venous ulcer

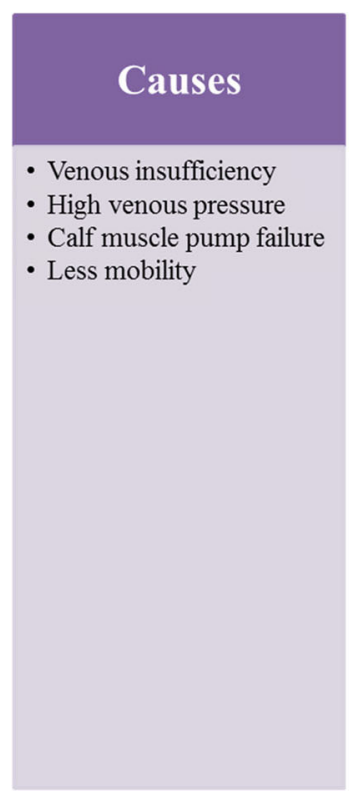

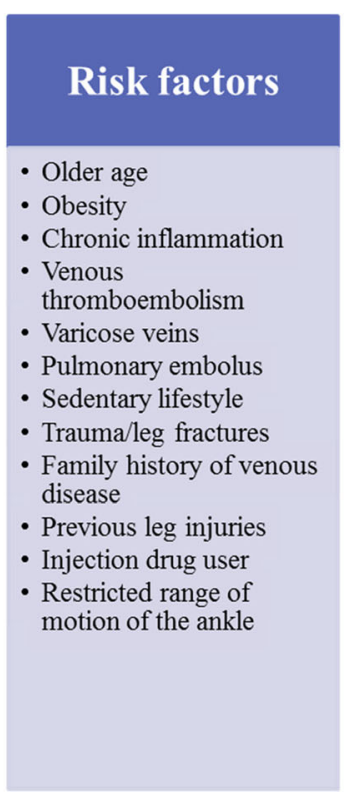

Signs \& symptoms

- Swelling \& pain

- Unevenly shaped borders

- Redness \& warmth

- Itching \& tingling

- Pain \& tenderness

- Rapid increase in wound size

- Fever \& chills

- Unpleasant \& foulsmelling of wound exudates

- Heavy feeling in legs

- Red, flaky, scaly \& itchy skin

- Discolouration \& darkening of the borders

- High temperature 
systemic illness - rheumatoid arthritis, vasculitis, osteomyelitis and skin malignancy - also have a similar presentation and therefore require appropriate diagnosis [7]. A complete family history of the patients together with clinical presentation and physical examination should be taken in order to differentiate the venous ulcers from other lower extremity ulcers [1]. Venous ulcers can be diagnosed clinically on the basis of anatomic location, morphology and a series of characteristic skin changes. However, examinations like ankle-brachial index, colour duplex ultrasonography, plethysmography and venography may be helpful in doubtful cases $[1,12]$. Supplementary Table 1 represents the differential diagnosis and Fig. 2 shows signs and symptoms of venous ulcer.

The CVD includes a detail continuum of venous conditions of lower limbs from early symptoms like telangiectasia or reticular veins, leg pain or oedema to complications like venous leg ulcers. Therefore, a common terminology on venous anatomy, the Clinical, Etiological, Anatomical, and Pathophysiological (CEAP) classification (Fig. 3), was proposed by the ad hoc committee of the American Venous Forum in 1994, revised in 2004, and has been subsequently accepted worldwide including India [13]. As per this classification, stages C5-C6 are categorised as venous ulcers. Figure 4 represents the flow chart for assessment and diagnosis of venous ulcer.

Recommendations

- A comprehensive assessment of both patient and ulcer with respect to history, clinical presentation and physical examination should be done in order to find out the aetiology and formulate a management plan for patients with venous ulcer. Clinical, Etiological, Anatomical, and Pathophysiological (CEAP) classification should be used to classify and identify the extent of venous disease. (Class I, Level of evidence B) $[11,13]$

- Venous ulcers can be diagnosed clinically on the basis of anatomic location, morphology and a series of characteristic skin changes. However, examinations including ankle-brachial index, Doppler tests, colour duplex ultrasonography, plethysmography and venography are the useful methods for assessment of venous ulcer and aid in differential diagnosis. (Class I, Level of evidence B) $[1,11]$

\section{Management}

The objective of venous ulcer management includes oedema reduction, improvement in ulcer healing and prevention of recurrence. The management (both prevention and treatment) options (detailed in Fig. 5) include:

- Dietary and lifestyle modification

- Medical management

- Dressing

- Compression therapy

- Operative or endovenous treatments
Though several treatment options are available for venous ulcers, the evidence is limited and inconsistent to support their use [15]. Supplementary Table 2 shows venous ulcer management options recommended by various societies.

\section{Recommendations}

The management of venous ulcer must be multidisciplinary and should include detail history, physical examination and diagnosis and basic and newer treatment modalities with proper patient education regarding diet and lifestyle modification. (Class I, Level of evidence C) [14]

\section{Dietary and Lifestyle Modification}

Although limited data are available for the dietary and lifestyle modification, existing literature suggests that these parameters have a vital role in pain relief and preventing recurrence [16-18]. Dietary modifications, nutritional enhancements, smoking cessation, weight reduction, maintaining a healthy cardiac status and a strong psychosocial support provide a positive outcome in patients with a history of venous leg ulcers [17]. Evidence advocates that a large body mass index (> $\left.33 \mathrm{~kg} / \mathrm{m}^{2}\right)$ and short walking distance $(<200 \mathrm{~m} /$ day $)$ were associated with slow wound healing [19]. Moreover, zinc supplement in patients with low zinc level improves the process of wound healing [20]. Deficiency of vitamin C and D was found high in patients with venous ulcer; therefore, diets rich in these vitamins may be supplemented to improve wound healing [21, 22].

Impaired calf muscle pump function significantly intensifies the risk of chronic venous insufficiency and aggravates the risk of venous ulcers [20]. Even though the mechanism is not clear, physical and isotonic exercise may enhance the ejecting ability of calf muscle pump, sequentially result in improved hemodynamic parameters and promote ulcer healing $[16,23,24]$. A 12 -week randomised clinical trial (RCT) demonstrated significantly greater (32\%) decrease in ulcer size $(P=0.34)$ and improvement in calf muscle pump function parameters [ejection fraction $(P=0.05)$, residual volume fraction $(P=0.04)$ ] and range of ankle motion $(P=0.01)$ with home-based progressive resistance exercise programme [25].

Leg elevation has been used for a long time and is still a recommended option. Elevation of the affected leg during sitting enhances venous return and avoids oedema and pain in leg [16]. Leg should be raised above the heart level, with the aim of improving microcirculation and oxygen delivery and hastening ulcer healing [1]. Leg elevation for $1 \mathrm{~h} /$ day was significantly associated with prevention of venous ulcer recurrence and 45\% increase of the laser Doppler flux (i.e., flow within veins) [26, 27]. In accordance with this evidence, several guidelines recommend leg elevation in the management of venous ulcers $[1,6,11,28]$. 


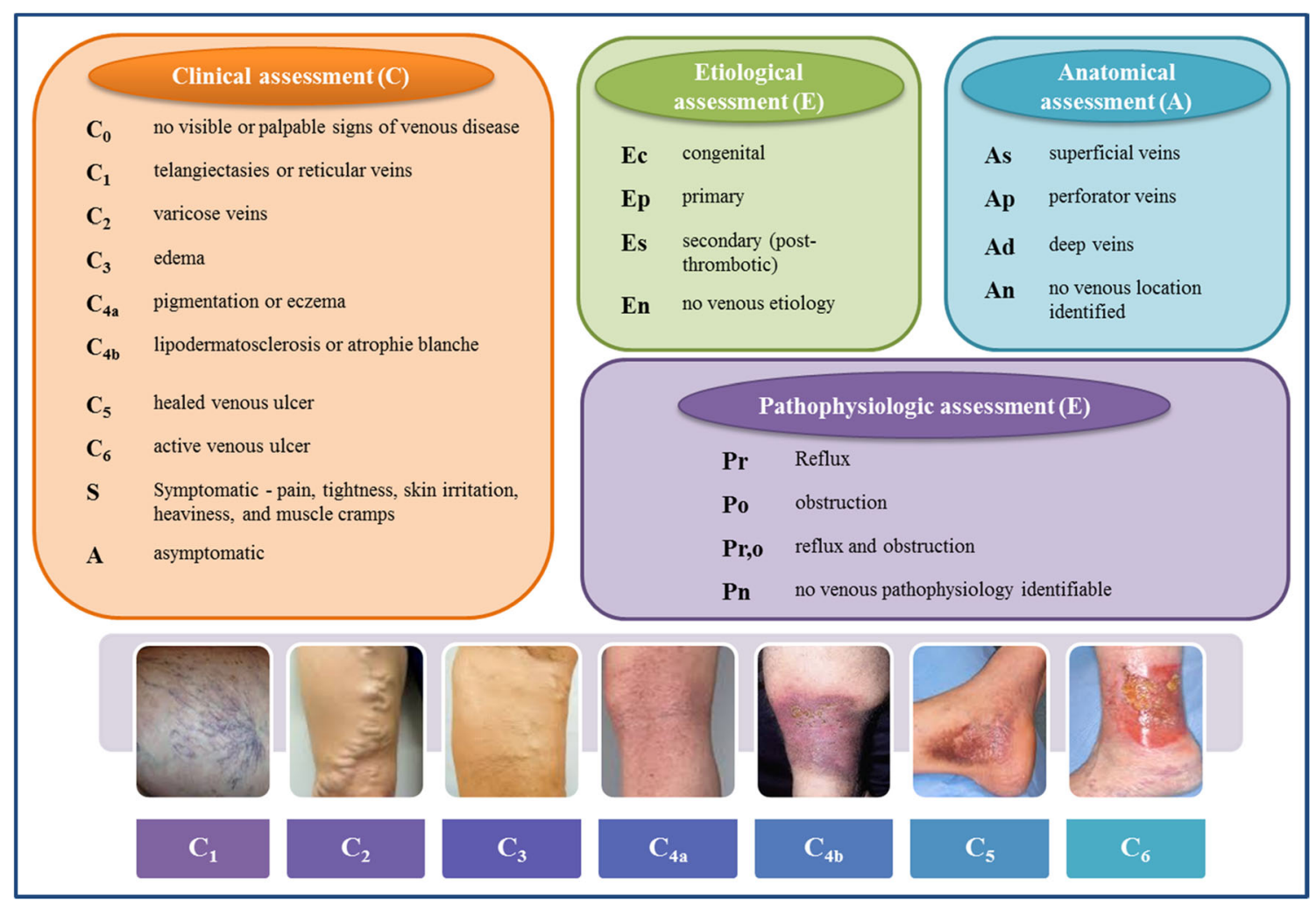

Fig. 3 Clinical, Etiological, Anatomical, and Pathophysiological (CEAP) classification system for chronic venous disease [6, 13]

Recommendations

- Dietary modifications, nutritional enhancements, smoking cessation, weight reduction, and maintaining a healthy cardiac status with a strong psychosocial support help in ulcer healing and improve quality of life in patients with venous ulcer. (Class I, Level of evidence C) [16, 17, 19]

- Progressive resistance exercise and leg elevation aid in ulcer healing, reduce ulcer pain and oedema and prevent ulcer recurrence. (Class IIA, Level of evidence B) [1, 6, 25-27]

\section{Medical Management}

Medical management of venous ulcer includes systemic and topical therapy.

\section{Systemic Therapy}

Systemic therapy can be used as an adjuvant to compression therapy or surgery. [29]. It is a valuable alternative in patients with failure of compression therapy and who opt out for surgery.

\section{Venoactive Drugs/Phlebotonics}

Phlebotonics are a heterogeneous class of drugs that strengthen blood vessel walls, increase venous tone and lymphatic drainage and normalise capillary permeability.
Supplementary Table 3 shows mode of action of these drugs. Micronised purified flavonoid fraction (MPFF) is the most commonly used venoactive drug [29]. It influences microcirculation through an inhibitory action on inflammatory process and reduction of venous wall permeability. MPFF modulates leukocyte adhesion, increases venous tone and protects cells from hypoxia [30, 31].

A Cochrane review examined the ulcer healing in adults receiving MPFF $1000 \mathrm{mg} /$ day in addition to standard treatment. The study showed a statistically significant effect in favour of MPFF (RR, 1.36; 95\% CI, 1.07 to 1.74 ) [30]. Similarly, a meta-analysis revealed that patients treated with adjunctive MPFF had $32 \%$ better chance of healing ulcers (relative risk reduction (RRR), 32\%; CI, 3-70\%) in 6 months [31]. MPFF displayed shorter time to healing (16 versus 21 weeks; $P=0.0034$ ) with the benefit seen especially in patients with 5- to $10-\mathrm{cm}^{2}$ ulcer area (RRR, $40 \%$; CI, 6-87\%) and 6-12 months of ulcer duration (RRR, 44\%; CI, 6-97\%). Moreover, MPFF shows beneficial outcomes without serious adverse events [32]. Subsequently, the working group for CVD agreed with previous guidance by the International European Society for Vascular Surgery (ESVS)-2015 recommending the use of MPFF for healing of venous ulcers, alone and adjunctive to compression therapy, and for the reduction in symptoms of CVD such as oedema [32]. Supplementary Table 4 describes key points of MPFF evidence. 
Fig. 4 The flow chart for assessment and diagnosis of venous ulcer [12]
Clinical, pain and ulcer history*

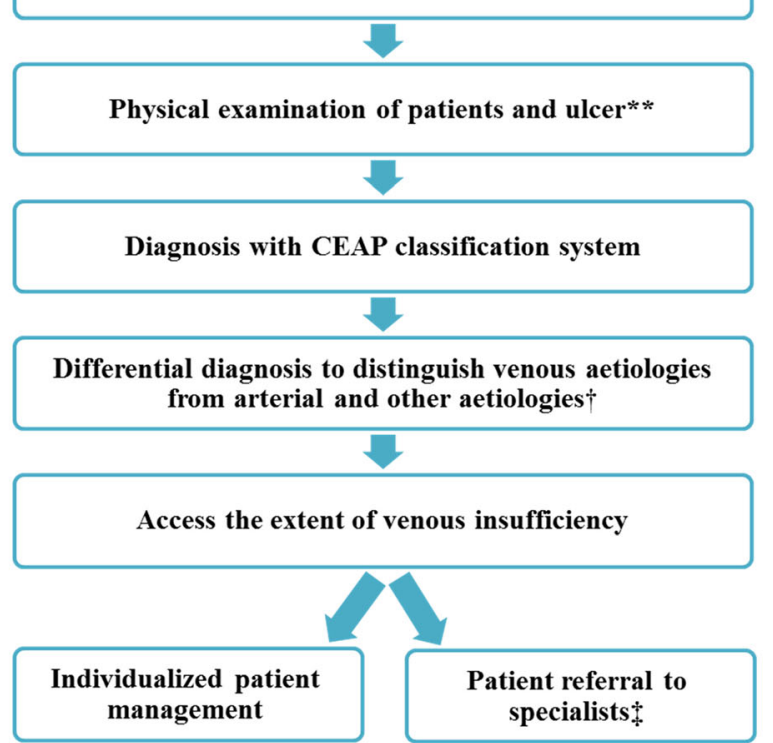

*clinical history includes family history of leg ulcer, varicose vein, previous/current DVT, obesity etc. pain history includes location, severity and quality of pain and its association with patients quality of life. ulcer history includes duration of ulcer and time taken and management option to treat previous ulcer.

**physical examination includes measurement of the ulcer size, amount and type of exudate, appearance of the ulcer bed, condition of the ulcer edges, and signs of clinical infection.

$\dagger$ differential diagnosis procedures includes ankle-brachial index, toe-brachial index, colour duplex ultrasonography, plethysmography, and venography

$\doteqdot$ in case of diagnostic uncertainty, suspicion of malignancy, ulcers not healed within 3 months, ulcers causing uncontrolled pain, and in any underlying disease condition patient may be referred to concerned specialists

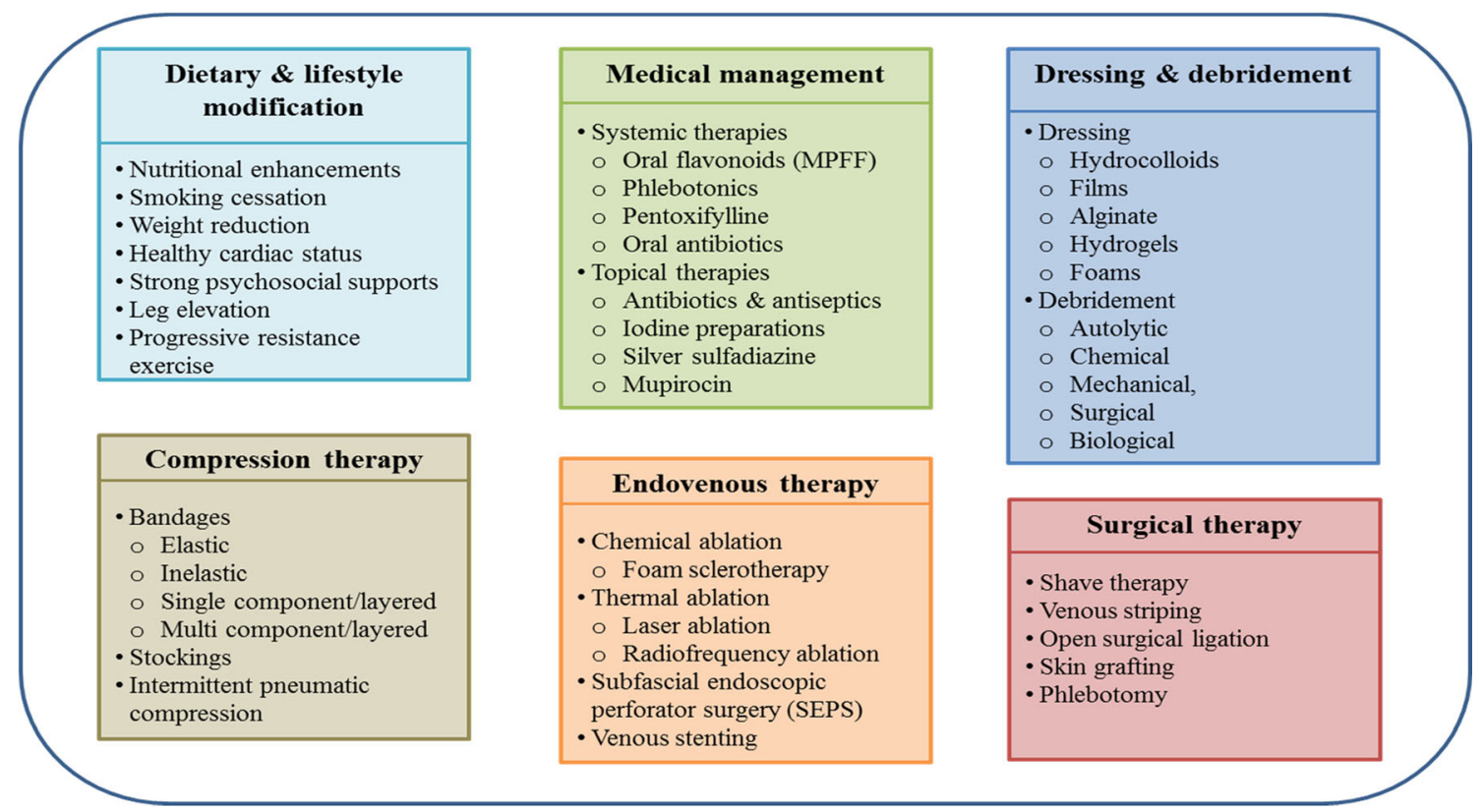

Fig. 5 Existing options for the management of venous ulcers $[1-3,6,11,14]$ 
Non-micronised diosmins or synthetic diosmins have relatively larger particle size leading to low absorption and bioavailability. Therefore, they show relatively reduced pharmacological activity as demonstrated in several RCTs [33-35].

Horse chestnut seed extract (oxerutin) [36] did not show efficacy, while rutin and hydroxyethylrutosides have limited high-quality evidence for their use [37, 38]. Calcium dobesilate given for 3 months did not show effect on QoL of CVD patients in an RCT [39]. In addition to its poor clinical efficacy, the risk of calcium dobesilate-induced agranulocytosis should also be considered [40, 41].

Pentoxifylline Pentoxifylline increases microcirculatory blood flow, improves peripheral tissue oxygenation, reduces blood viscosity and decreases the potential for platelet aggregation and thrombus formation [29]. Although several RCTs reported no improvement in healing time by pentoxifylline compared to placebo $[42,43]$, a recent Cochrane review demonstrated improved ulcer healing rates when used as an adjuvant to compression (RR, $1.56 ; 95 \%$, CI 1.14 to 2.13 ) or when used as solo therapy (RR, 2.25; 95\% CI, 1.49 to 3.39) [44]. Several guidelines recommend pentoxifylline for the treatment of long-standing or large venous leg ulcers in absence of any contraindications $[2,12]$.

Aspirin The role of aspirin in the management of venous ulcer remains unclear. Aspirin provides pain relief (analgesic), reduces inflammation and stops blood cells from aggregation, which subsequently prevents formation of blood clots. Aspirin may improve the healing time and reduce the number of recurrent ulcer episodes. Though several RCTs reported that aspirin reduces the healing time and ulcer surface area compared to placebo [45, 46], a recent Cochrane systematic review did not reach a definitive conclusion about the benefits and harms of the healing and recurrence of venous ulcers [47]. In this line, the ongoing Low Dose Aspirin for Venous Leg Ulcers (Aspirin4VLU) trial and Aspirin for Venous Ulcers: Randomised Trial (AVURT) may address the efficacy and safety of aspirin in these patients [48, 49].

Statins Statins, due to their wound healing property, can be used as adjuvant therapy. Current research advocates that statins have a positive immune-modulatory role, improve microvascular function and reduce oxidative stress, thereby promote wound healing [50]. A recent RCT reported that daily adjunct simvastatin $(40 \mathrm{mg})$ produced a significant improvement in healing rate and time $(P<0.001)$ and also improved patient quality of life $(P<0.001)$ compared to placebo [51].

Oral Antibiotics Systemic antibiotics have no routine role in promoting healing of venous ulcers when there is no sign of infection as reported by a Cochrane review [52].

\section{Anti-MMPs/Doxycycline}

Several metalloproteinases (MMPs) such as MMP-1, MMP-8 and MMP-9 seem to be involved in the onset and healing phases of venous ulcer [53]. A randomised study reported that sub-antimicrobial doses of doxycycline quicken the healing of chronic venous leg ulcer through the inhibition of MMP-9, neutrophil gelatinase-associated lipocalin and vascular endothelial growth factor activation [49]. However, a Cochrane review concluded that there is no randomised evidence on the impact of a "test and treat policy" for protease levels on outcomes [50].

\section{Topical Therapy}

Various topical antibiotics and antiseptics, iodine preparations, silver sulfadiazine and mupirocin are used in the healing of venous ulcers. However, evidence and guidelines recommend that topical agents can be used only if there is a sign of local infection $[2,15,17]$. A Cochrane review supported the use of povidone-iodine but did not advocate the routine use of honey or silver-based products in the healing of venous ulcers [52].

\section{Recommendations}

- Medical management with MPFF, either alone or in combination with standard therapy, heals venous ulcers, reduces symptoms and pain and shortens healing time. (Class I, Level of evidence A) [30, 32]

- MPFF $1000 \mathrm{mg} /$ day for 6 months as an adjuvant therapy is recommended in all patients with venous ulcer. (Class I, Level of evidence A) [54-56]

- Non-micronised or synthetic diosmins are inefficient as compared to MPFF in the management of venous ulcers. (Class III, Level of evidence A) $[34,35]$

- Other flavonoids like rutins, oxerutins and hydroxyethylrutosides have limited evidence for their use in management of venous ulcer. (Class IIB, Level of evidence A) [36-38]

- Calcium dobesilate may not be routinely recommended for the management of venous ulcer due to poor efficacy and risk of agranulocytosis. (Class III, Level of evidence B) [39-41]

- In absence of any contraindications, pentoxifylline in addition to standard compression therapy can be used for the management of long-standing or large venous ulcers. (Class IIA, Level of evidence A) $[2,12,42]$

- Oral aspirin has no significant effect in ulcer management and hence not routinely recommended. (Class II, Level of evidence A) [11, 47]

- Statins as adjuvant therapy to standard treatment of venous ulcer heal ulcer and improve quality of life. (Class I, Level of evidence B) [50, 51]

- Unless venous ulcer is infected, topical agents and topical/oral antibiotics have no role in the management of venous ulcer. (Class III, Level of evidence A) $[2,14,17,50,52]$

\section{Dressing}

Dressing with or without any active material accelerates the process of wound healing by regulating wound moisture and enhancing hydration of the affected site [57]. Moreover, they 
promote autolytic debridement, regulate exudate, control wound infection, ease the pain and are economical [14]. Sometimes dressing is placed before compression bandages or hosiery in order to avoid the bandages sticking to the wound [58]. In the recent times, interactive and active dressings are used widely rather than passive dressings. Various types of dressings like films, hydrocolloids, hydrogels, alginates and foams are used in the healing of the venous ulcers (Fig. 5).

Vacuum-Assisted Closure (VAC) system increases blood flow, accelerates the granulation tissue formation and reduces oedema by applying a regulated continuous or intermittent pressure [59]. Evidence reported that VAC therapy as an adjuvant in the management of venous ulcers is effective [59-61]. A systematic review and meta-analysis reported that silver-impregnated dressings improve the short-term healing of ulcers; however, their long-term effects remain unclear [62]. Honey-impregnated dressings have no significant effect on healing of venous ulcer [63]. A recent Cochrane review shows that differences in efficacy and safety between protease-modulating matrix (PMM) and non-PMM dressing are in conclusive [64]. There was no difference between types of dressing for the management of venous ulcer and they did not show efficacy when used beneath compression [64, 65].

Recommendations

- There are no difference in the types of dressing in terms of efficacy and cost-effectiveness when used for the management of venous ulcer. Moreover, dressings may be used beneath compression for ulcer healing. (Class III, Level of evidence A) [58, 64, 65]

- Dressing impregnated with povidone-iodine, silver, but not with honey, can be used for healing of venous ulcer when there is a sign of clinical infection. (Class II, Level of evidence B) [14, 52, 63]

- Vacuum Assisted Closure (VAC) therapy and protease-modulating matrix (PMM) treatments may improve ulcer healing. (Class II, Level of evidence B) [59-61, 64]

\section{Compression Therapy}

Compression therapy is the cornerstone of management in patients with venous ulcers [1, 66, 67]. Compression is established with a simple concept that employs an external pressure to the limb, which in turn improves venous haemodynamic [14]. Compression therapies are broadly categorised into bandages, stockings (hosieries) and intermittent pneumatic compression (IPC) (Fig. 5). Further, bandages may be either elastic and inelastic or single or multi-layered [68].

Compression reduces oedema, recovers venous reflux, improves ulcer healing and lowers pain with a success rate of 30 $60 \%$ at 6 months and $70-85 \%$ after 1 year. However, factors like pain, drainage and difficulty in application limit its applicability [1]. Supplementary Table 5 shows a summary of studies evaluating compression techniques [69-76]. A Cochrane review revealed that compression increases ulcer healing rates; multicomponent and elastic bandage systems are more effective than single-component and inelastic bandage systems, respectively [77]. Both four layer bandages (4LB) and two-layer bandages (2LB) are found to be equally effective in the management of venous ulcers; however, 2LB system may be easier to apply than 4LB system [71]. Moreover, IPC may be used in absence or unsuitability of other compression options [67].

Recommendations

- Compression therapy is recommended over no compression for management of venous ulcer. (Class I, Level of evidence A) [77]

- Both compression bandages and stocking are equally effective in healing venous ulcers. However, compression stocking is a cost-effective approach and may reduce the risk of ulcer recurrence. (Class I, Level of evidence B) [69, 70]

- Four-layer compression bandages with a high compression pressure of $40 \mathrm{mmHg}$ is effective in healing ulcers. (Class I, Level of evidence B) [72]

- There is no such significant difference between 4LB and 2LB in the management of venous ulcers; however, 2LB system is easier to apply than 4LB. (Class II, Level of evidence A) [71, 77]

- Multicomponent compression systems containing an elastic bandage may be more effective than those composed mainly of inelastic constituents. (Class I, Level of evidence A) [77]

- Intermittent pneumatic compression system may be used for symptom relief when other compression options are not available or cannot be used or have failed (Class I, Level of evidence A) [11, 14, 78]

\section{Operative or Endovenous Treatments}

The primary goal of operative or endovenous treatment is to accelerate the healing process and prevent recurrence [14]. Operative procedure for venous ulcer has shown $88 \%$ ulcer healing rate with only $13 \%$ recurrence rate over 10 months; however, there is no evidence for the superiority of surgical procedure over medical management [1].

\section{Minimally Invasive Procedures}

Foam sclerotherapy, endoablation like laser or radiofrequency ablation, subfascial endoscopic perforator surgery (SEPS) and venous stenting are some of the minimally invasive procedures used for the management of venous ulcers (Fig. 5).

Evidence reported that ablation of incompetent superficial and perforator veins in 110 venous ulcer patients (140 procedures; 74 superficial and 66 perforators) after the failure of conventional compression therapy was associated with a significant and measurable reduction in ulcer size and ultimate healing [79]. Furthermore, endovenous ablation of incompetent superficial and perforating veins with compression reduces ulcer recurrence compared with compression alone in 
Fig. 6 Management flow sheet for patients with venous ulcers

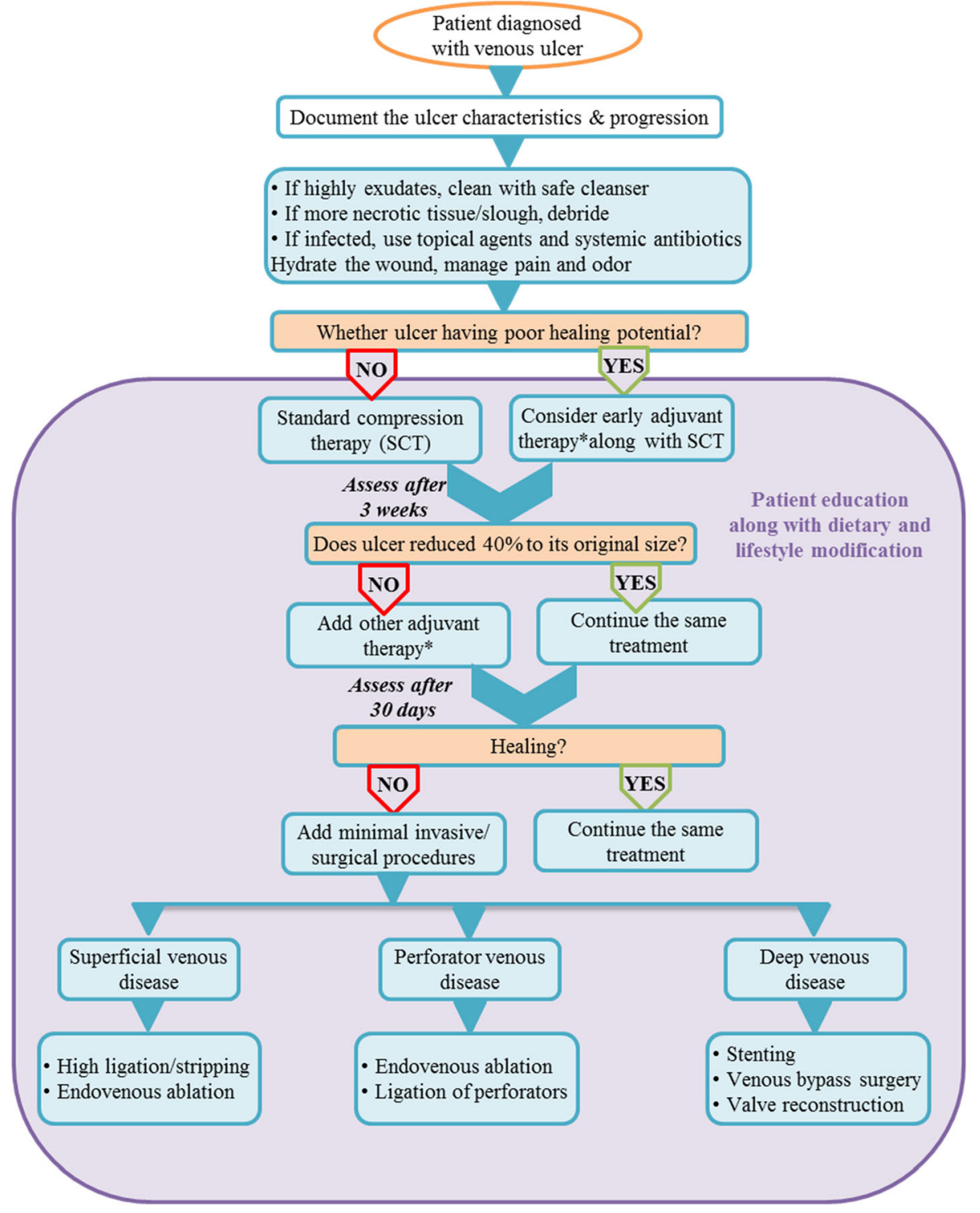

*Adjuvant therapies includes medical management with oral flavonoid (MPFF), pentoxifylline, aspirin, statins, and dressing, debridement, etc. patients with healed venous ulcers [80]. Foam sclerotherapy in addition to compression attributed $96 \%$ of healing within 3 months and only two healed ulcers $(7 \%)$ had recurrence at 12 months [81]. Moreover, minimally invasive ablation of superficial axial and perforator vein reflux in combination with compression therapy is safe and promotes quicker healing in patients with active chronic venous ulcer [82]. Nonetheless, a Cochrane review identifies a need of wellcontrolled RCTs and prospective studies to effectively use minimally invasive ablation procedures in the management of venous ulcers [83].

Recommendations

- Sclerotherapy either in the form of foam or liquid is an attractive alternative to surgery, especially for the elderly and frail patient for the (continued)

management of venous ulcer with superficial venous reflux. (Class II, Level of evidence B) $[11,81,84]$

- Foam sclerotherapy in addition to standard compression heals ulcer and reduces the risk of recurrence. (Class I, Level of evidence B) [11, 81, $84,85]$

- Endovenous ablation of incompetent superficial and perforator veins in addition to compression promotes quicker healing and reduces the risk of recurrence. (Class I, Level of evidence C) [79, 80, 82, 83]

\section{Surgical Procedures}

Surgical debridement, shave therapy, venous striping and phlebotomy are the various surgical procedures used for the management of venous ulcers (Fig. 5). Surgical debridement 
options available today include autolytic, chemical, mechanical, surgical and biological modalities [17].

A recent RCT revealed a significantly higher ulcer free incidence ( 58.9 vs. $39.6 \%, P=0.007)$ and low recurrence rate (48.9 vs. $94.3 \%$ ) with surgical treatment (combined superficial and perforating vein surgery) compared to conservative therapy (ambulatory compression therapy) [86]. Superficial venous surgery and conservative compression treatment showed similar ulcer healing rates; however, ulcer recurrence was lower with surgery in a systematic review [87]. Linking to the same outcome, the ESCHAR trial reported that, after 24 weeks, ulcer recurrence rate was halved in patients who underwent surgery regardless of the presence of deep vein incompetence [88]. Meanwhile, each underlying pathology associated with venous ulcer has several surgical treatment options with no clear evidence about which is the safest and most effective method. Figure 6 represents a proposed patient flow sheet for the management of venous ulcer.

Recommendations

- Surgical procedures with patient individualization may be suggested over standard treatments in management of venous ulcer. (Class I, Level of evidence A) $[1,86,87]$

- Each underlying pathology associated with venous ulcer has several surgical treatment options with no clear evidence about which is the safest and most effective method in healing the ulcer. (Class II, Level of evidence C) [1]

\section{Ulcer Recurrence}

After achieving healing, it is important to do its follow-up for reducing the risk of recurrence. A surgical procedure in addition to compression therapy is more effective in preventing the risk of recurrence compared to other treatment options $[2,14]$. Figure 6 illustrates the management options for different pathological conditions to prevent recurrence. In addition, compression therapy should be used continuously to reduce the recurrence risk [12, 89]. Moreover, diet and lifestyle modification including progressive resistance exercise, patient education, leg elevation, weight reduction, maintaining a healthy cardiac status and strong psychosocial supports are likely to benefit for preventing the risk of recurrence $[12,16,18]$.

Recommendations

- Surgical procedures are effective in reducing the risk of ulcer recurrence compared to conservative procedures. (Class I, Level of evidence A) $[2,14,86,87]$

- Diet and lifestyle modification along with continuous use of compression reduce the risk of ulcer recurrence. (Class I, Level of evidence B) $[12,89]$

\section{Conclusion}

The management of venous ulcers poses a significant therapeutic challenge. A comprehensive evaluation of the patient and ulcer is required to determine aetiology and to frame an appropriate management plan. Though several treatment options are available for venous ulcers, there is an inconsistent evidence to support their use. Medical management with MPFF should be used along with standard treatments in order to obtain numerous beneficial outcomes. Compression therapy is the mainstay of the treatment approach for venous ulcers; however, surgical options can be considered in the failure of compression therapy. Endovenous/operative and compression therapies have similar rates of ulcer healing; however, surgical treatment provides less risk of recurrence. The management of venous ulcer must be multidisciplinary and should include detailed history, physical examination and diagnosis and basic and newer treatment modalities with proper patient education regarding diet and lifestyle modification.

\section{Compliance with Ethical Standards}

Conflict of Interests All the authors declare that they have no conflict of interest.

\section{References}

1. Collins L, Seraj S (2010) Diagnosis and treatment of venous ulcers. Am Fam Physician 81(8):989-996

2. O'Donnell TF, Passman MA (2014) Clinical practice guidelines of the Society for Vascular Surgery (SVS) and the American Venous Forum (AVF) - management of venous leg ulcers. Introduction J Vasc Surg 60(2 Suppl):1S-2S. https://doi.org/10.1016/j.jvs.2014. 04.058

3. Agale SV (2013) Chronic leg ulcers: epidemiology, aetiopathogenesis, and management. Ulcers 2013:1-9. https://doi. org $/ 10.1155 / 2013 / 413604$

4. Nelzen O (2008) Prevalence of venous leg ulcer: the importance of the data collection method. Phlebolymphology 15(4):143-150

5. Pinjala RK, Abraham TK, Chadha SK, Hai AA, Hussain SA, Moulik AK, Nagori LF, Nayak G, Patel MD, Sen G, Shetty SV, Sinha KN (2004) Long-term treatment of chronic venous insufficiency of the leg with micronized purified flavonoid fraction in the primary care setting of India. Phlebology 19(4):179-184. https:// doi.org/10.1258/0268355042555028

6. Dekiwadia DB, Jindal R, Varghese R, Bedi HS, Padaria S, Patel MD, Agarwal S, Saravanan S, Rao UV, Pinjala R, Singh G (2016) Executive summary: a consensus statement-part I: recommendations for the management of chronic venous disease (CVD) in India and key role of primary care doctors. J Assoc Physicians India 64(8):53-56

7. Prakash S, Tiwary SK, Mishra M, Khanna AK (2013) Venous ulcer. Surg Sci 4(2):144-150. https://doi.org/10.4236/ss.2013.42028

8. Ramamoorthy P (2013) The growing threat of chronic venous disease. Medicine update Jaypee Brothers Medical Publishers Pvt Ltd: 753-756 
9. Langer V (2014) Leg ulcers: an Indian perspective. Indian Dermatol Online J 5(4):535-536. https://doi.org/10.4103/22295178.142559

10. Vishwanath V (2014) Venous leg ulcer: management aspect in Indian scenario. Indian Dermatol Online J 5(3):396. https://doi. org/10.4103/2229-5178.137827

11. Wittens CD, Davies AH, Bækgaard N, Broholm R, Cavezzi A, Chastanet $\mathrm{S}$ et al (2015) Editor's choice - management of chronic venous disease: clinical practice guidelines of the European Society for Vascular Surgery (ESVS). Eur J Vasc Endovasc Surg 49(6): 678-737. https://doi.org/10.1016/j.ejvs.2015.02.007

12. Angel D, Barker J, Blanchfield D, Carville K, Haesler E, Hillier S et al (2011) Australian and New Zealand clinical practice guideline for prevention and management of venous leg ulcers 2011

13. Eklöf B, Rutherford RB, Bergan JJ, Carpentier PH, Gloviczki P, Kistner RL, Meissner MH, Moneta GL, Myers K, Padberg FT, Perrin M, Ruckley CV, Smith PC, Wakefield TW, American Venous Forum International Ad Hoc Committee for Revision of the CEAP Classification et al (2004) Revision of the CEAP classification for chronic venous disorders: consensus statement. J Vasc Surg 40(6):1248-1252. https://doi.org/10.1016/j.jvs.2004.09.027

14. Zenilman J, Valle MF, Malas MB, Maruthur N, Qazi U, Suh Y et al (2013) Chronic venous ulcers: a comparative effectiveness review of treatment modalities [Internet]. Rockville (MD): Agency for Healthcare Research and Quality (US). Available from http:// www.ncbi.nlm.nih.gov/books/NBK179152/

15. Franks PJ, Barker J, Collier M, Gethin G, Haesler E, Jawien A, Laeuchli S, Mosti G, Probst S, Weller C (2016) Management of patients with venous leg ulcers: challenges and current best practice. J Wound Care 25(Sup6):S1-S67. https://doi.org/10.12968/jowc. 2016.25.Sup6.S1

16. Shenoy MM (2014) Prevention of venous leg ulcer recurrence. Indian Dermatol Online J 5(3):386-389. https://doi.org/10.4103/ 2229-5178.137824

17. Dogra S, Sarangal R (2014) Summary of recommendations for leg ulcers. Indian Dermatol Online J 5(3):400-407. https://doi.org/10. 4103/2229-5178.137829

18. Rai R (2014) Standard guidelines for management of venous leg ulcer. Indian Dermatol Online J 5(3):408-411. https://doi.org/10. 4103/2229-5178.137830

19. Milic DJ, Zivic SS, Bogdanovic DC, Karanovic ND, Golubovic ZV (2009) Risk factors related to the failure of venous leg ulcers to heal with compression treatment. J Vasc Surg 49(5):1242-1247

20. White-Chu EF, Conner-Kerr TA (2014) Overview of guidelines for the prevention and treatment of venous leg ulcers: a US perspective. J Multidiscip Healthc 7:111-117. https://doi.org/10.2147/JMDH. S38616

21. Lazareth I, Hubert S, Michon-Pasturel U, Priollet P (2007) Vitamin $\mathrm{C}$ deficiency and leg ulcers. A case control study. J Mal Vasc 32(2): 96-99. https://doi.org/10.1016/j.jmv.2007.02.003

22. Burkievcz CJ, Skare TL, Malafaia O, Nassif PA, Ribas CS, Santos LR (2012) Vitamin D deficiency in patients with chronic venous ulcers. Rev Col Bras Cir 39(1):60-63. https://doi.org/10.1590/ S0100-69912012000100012

23. Yang D, Vandongen YK, Stacey MC (1999) Effect of exercise on calf muscle pump function in patients with chronic venous disease. Br J Surg 86(3):338-341

24. Kan YM, Delis KT (2001) Hemodynamic effects of supervised calf muscle exercise in patients with venous leg ulceration: a prospective controlled study. Arch Surg 136(12):1364-1369. https://doi. org/10.1001/archsurg.136.12.1364

25. O'Brien J, Edwards H, Stewart I, Gibbs H (2013) A home-based progressive resistance exercise programme for patients with venous leg ulcers: a feasibility study. Int Wound J 10(4):389-396. https:// doi.org/10.1111/j.1742-481X.2012.00995.x
26. Finlayson K, Edwards H, Courtney M (2011) Relationships between preventive activities, psychosocial factors and recurrence of venous leg ulcers: a prospective study. J Adv Nurs 67(10):2180 2190

27. Abu-Own A, Scurr JH, Smith PD (1994) Effect of leg elevation on the skin microcirculation in chronic venous insufficiency. J Vasc Surg 20(5):705-710. https://doi.org/10.1016/S0741-5214(94) 70157-1

28. (2010) Management of chronic venous leg ulcers. A national clinical guideline. SIGN Publication

29. Nicolaides A, Kakkos S, Eklof B, Perrin M, Nelzen O, Neglen P et al (2014) Management of chronic venous disorders of the lower limbs - guidelines according to scientific evidence. Int Angiol 33(2):87-208

30. Scallon C, Bell-Syer SE, Aziz Z (2013) Flavonoids for treating venous leg ulcers. Cochrane Database Syst Rev 5:CD006477

31. Coleridge-Smith P, Lok C, Ramelet AA (2005) Venous leg ulcer: a meta-analysis of adjunctive therapy with micronized purified flavonoid fraction. Eur J Vasc Endovasc Surg 30(2):198-208

32. Bush R, Comerota A, Meissner M, Raffetto JD, Hahn SR, Freeman $\mathrm{K}$ (2017) Recommendations for the medical management of chronic venous disease: the role of micronized purified flavanoid fraction (MPFF) recommendations from the Working Group in Chronic Venous Disease (CVD) 2016. Phlebology 32(1_suppl):3-19

33. Maggioli A (2016) Chronic venous disorders: pharmacological and clinical aspects of micronized purified flavonoid fraction. Phlebolymphology 23(2):82-91

34. Cospite M, Dominici A (1988) Double blind study of the pharmacodynamic and clinical activities of $5682 \mathrm{SE}$ in venous insufficiency. Advantages of the new micronized form. Int Angiol 8(4 Suppl): 61-65

35. Amato C (1994) Advantage of a micronized flavonoidic fraction in comparison with a nonmicronized diosmin. Angiology 45(6 Pt 2): 531-536. https://doi.org/10.1177/000331979404500606

36. Leach MJ, Pincombe J, Foster GW (2006) Clinical efficacy of horse chestnut seed extract in the treatment of venous ulceration. J Wound Care 15(4):159-167

37. Stegmann W, Hubner K, Deichmann B, Muller B (1987) Efficacy of O-(beta-hydroxyethyl)-rutosides in the treatment of venous leg ulcers. Phlebologie 40(1):149-156

38. Wright DD, Franks PJ, Blair SD, Backhouse CM, Moffatt C, McCollum CN (1991) Oxerutins in the prevention of recurrence in chronic venous ulceration: randomized controlled trial. Br J Surg 78(10):1269-1270. https://doi.org/10.1002/bjs.1800781039

39. Martinez-Zapata MJ, Moreno RM, Gich I, Urrútia G, Bonfill X (2008) A randomized, double-blind multicentre clinical trial comparing the efficacy of calcium dobesilate with placebo in the treatment of chronic venous disease. Eur J Vasc Endovasc Surg 35(3): 358-365. https://doi.org/10.1016/j.ejvs.2007.08.012

40. Ibáñez L, Ballarín E, Vidal X, Laporte JR (2000) Agranulocytosis associated with calcium dobesilate. Eur J Clin Pharmacol 56(9): 763-767. https://doi.org/10.1007/s002280000190

41. Zapater P, Horga JF, García A (2003) Risk of drug-induced agranulocytosis: the case of calcium dobesilate. Eur J Clin Pharmacol 58(11):767-772. https://doi.org/10.1007/s00228002-0550-6

42. Dale JJ, Ruckley CV, Harper DR, Gibson B, Nelson EA, Prescott RJ (1999) Randomised, double blind placebo controlled trial of pentoxifylline in the treatment of venous leg ulcers. BMJ 319(7214):875-878. https://doi.org/10.1136/bmj.319.7214.875

43. Nelson EA, Prescott RJ, Harper DR, Gibson B, Brown D, Ruckley CV (2007) A factorial, randomized trial of pentoxifylline or placebo, four-layer or single-layer compression, and knitted viscose or hydrocolloid dressings for venous ulcers. J Vasc Surg 45(1):134 141. https://doi.org/10.1016/j.jvs.2006.09.043 
44. Jull AB, Arroll B, Parag V, Waters J (2012) Pentoxifylline for treating venous leg ulcers. Cochrane Database Syst Rev 12: CD001733

45. Layton AM, Goodfield MJ, Ibbotson S, Davies JA (1994) Randomised trial of oral aspirin for chronic venous leg ulcers. Lancet 344(8916):164-165. https://doi.org/10.1016/S01406736(94)92759-6

46. del Río Solá ML, Antonio J, Fajardo G, Puerta CV (2012) Influence of aspirin therapy in the ulcer associated with chronic venous insufficiency. Ann Vasc Surg 26(5):620-629. https://doi.org/10.1016/ j.avsg.2011.02.051

47. de Oliveira Carvalho PE, Magolbo NG, De Aquino RF, Weller CD (2016) Oral aspirin for treating venous leg ulcers. Cochrane Database Syst Rev 2:CD009432

48. Jull A, Wadham A, Bullen C, Parag V, Kerse N, Waters J (2016) Low-dose aspirin as an adjuvant treatment for venous leg ulceration: study protocol for a randomized controlled trial (Aspirin4VLU). J Adv Nurs 72(3):669-679. https://doi.org/10. 1111/jan.12864

49. Tilbrook H, Forsythe RO, Rolfe D, Clark L, Bland M, Buckley H et al (2015) Aspirin for Venous Ulcers: Randomised Trial (AVURT): study protocol for a randomised controlled trial. Trials 6(1):513

50. Raposio E, Libondi G, Bertozzi N, Grignaffini E, Grieco MP (2015) Effects of topic simvastatin for the treatment of chronic vascular cutaneous ulcers: a pilot study. J Am Coll Clin Wound Spec 7(1-3): 13-18. https://doi.org/10.1016/j.jccw.2016.06.001

51. Evangelista MT, Casintahan MF, Villafuerte LL (2014) Simvastatin as a novel therapeutic agent for venous ulcers: a randomized, double-blind, placebo-controlled trial. Br J Dermatol 170(5):11511157. https://doi.org/10.1111/bjd.12883

52. O'Meara S, Al-Kurdi D, Ologun Y, Ovington LG, Martyn-St James M, Richardson R (2014) Antibiotics and antiseptics for venous leg ulcers. Cochrane Database Syst Rev (1):CD003557

53. Amato B, Coretti G, Compagna R, Amato M, Buffone G, Gigliotti D (2015) Role of matrix metalloproteinases in non-healing venous ulcers. Int Wound J 12(6):641-645. https://doi.org/10.1111/iwj. 12181

54. Guilhou JJ, Dereure O, Marzin L, Ouvry P, Zuccarelli F, Debure C, van Landuyt H, Gillet-Terver MN, Guillot B, Levesque H, Mignot J, Pillion G, Février B, Dubeaux D (1997) Efficacy of MPFF in venous leg ulcer healing: a double-blind, randomised, controlled versus placebo trial in 107 patients. Angiology 48(1):77-85. https://doi.org/10.1177/000331979704800113

55. Glinski W, Chodynicka B, Roszkiewicz J, Bogdanowski T, Lecewicz-Torun B, Kaszuba A et al (1999) The beneficial augmentative effect of micronised purified flavonoid fraction (MPFF) on the healing of leg ulcers: an open, multicentre, controlled, randomised study. Phlebology 14(4):151-157. https://doi.org/10. 1177/026835559901400405

56. Roztocil K, Stvrtinová V, Strejcek J (2003) Efficacy of a 6-month treatment with MPFF in patients with venous leg ulcers associated with chronic venous insufficiency. Int Angiol 22(1):24-31

57. Dogra S, Rai R (2014) Venous leg ulcer: topical treatment, dressings and surgical debridement. Indian Dermatol Online J 5(3):371973. https://doi.org/10.4103/2229-5178.137820

58. Palfreyman S, Nelson EA, Michaels JA (2007) Dressings for venous leg ulcers: systematic review and meta-analysis. BMJ 335(7613):244. https://doi.org/10.1136/bmj.39248.634977.AE

59. Jiburum BC, Opara KO, Nwagbara IC (2011) Experience with vacuum-assisted closure device in the management of benign chronic leg ulcers. J West Afr Coll Surg 1(1):89-100

60. Leclercq A, Labeille B, Perrot JL, Vercherin P, Cambazard F (2016) Skin graft secured by VAC (vacuum-assisted closure) therapy in chronic leg ulcers: a controlled randomized study. Ann Dermatol Venereol 143(1):3-8
61. Körber A, Franckson T, Grabbe S, Dissemond J (2008) Vacuum assisted closure device improves the take of mesh grafts in chronic leg ulcer patients. Dermatology 216(3):250-256. https://doi.org/10. $1159 / 000112937$

62. Carter MJ, Tingley-Kelley K, Warriner RA (2010) Silver treatments and silver-impregnated dressings for the healing of leg wounds and ulcers: a systematic review and meta-analysis. J Am Acad Dermatol 63(4):668-679

63. Jull A, Walker N, Parag V, Molan P, Rodgers A (2008) Randomized clinical trial of honey-impregnated dressings for venous leg ulcers. Br J Surg 95(2):175-182

64. Westby MJ, Norman G, Dumville JC, Stubbs N, Cullum N (2016) Protease-modulating matrix treatments for healing venous leg ulcers. Cochrane Database Syst Rev 12:CD011918

65. O'Meara S, Martyn-St James M, Adderley UJ (2015) Alginate dressings for venous leg ulcers. Cochrane Database Syst Rev 8: CD010182

66. Mauck KF, Asi N, Elraiyah TA, Undavalli C, Nabhan M, Altayar O et al (2014) Comparative systematic review and meta-analysis of compression modalities for the promotion of venous ulcer healing and reducing ulcer recurrence J Vasc Surg 60(2):71S-90S. e1-2

67. Ratliff CR, Yates S, McNichol L, Gray M (2016) Compression for primary prevention, treatment, and prevention of recurrence of venous leg ulcers: an evidence-and consensus-based algorithm for care across the continuum. J Wound Ostomy Continence Nurs 43(4):347-364. https://doi.org/10.1097/WON.0000000000000242

68. Nair B (2014) Compression therapy for venous leg ulcers. Indian Dermatol Online J 5(3):378-382. https://doi.org/10.4103/22295178.137822

69. Ashby RL, Gabe R, Ali S, Saramago P, Chuang LH, Adderley U, Bland JM, Cullum NA, Dumville JC, Iglesias CP, Kang'ombe AR, Soares MO, Stubbs NC, Torgerson DJ (2014) VenUS IV (Venous Leg Ulcer Study IV) - compression hosiery compared with compression bandaging in the treatment of venous leg ulcers: a randomised controlled trial, mixed-treatment comparison and decision-analytic model. Health Technol Assess 18(57):1-293, vvi. https://doi.org/10.3310/hta18570

70. Finlayson KJ, Courtney MD, Gibb MA, O'Brien JA, Parker CN, Edwards HE (2014) The effectiveness of a four-layer compression bandage system in comparison with Class 3 compression hosiery on healing and quality of life in patients with venous leg ulcers: a randomised controlled trial. Int Wound J 11(1):21-27. https://doi. org/10.1111/j.1742-481X.2012.01033.x

71. Lazareth I, Moffatt C, Dissemond J, Lesne Padieu AS, Truchetet F, Beissert $S$ et al (2012). Efficacy of two compression systems in the management of VLUs: results of a European RCT. J Wound Care. 21(11):553-4, 556, 558 passim

72. Szewczyk MT, Jawień A, Cierzniakowska K, Cwajda-Białasik J, Mościcka P (2010) Comparison of the effectiveness of compression stockings and layer compression systems in venous ulceration treatment. Arch Med Sci 6(5):793-799

73. Kapp S, Miller C, Donohue L (2013) The clinical effectiveness of two compression stocking treatments on venous leg ulcer recurrence: a randomized controlled trial. Int J Low Extrem Wounds 12(3):189-198

74. Harper DR, Ruckley CV, Gibson B, Brown D, Prescott RJ (1999) Randomised trial of two grades of compression stockings in the prevention of venous ulcer recurrence- 5 year outcomes. Phlebology 14(91)

75. Wong IK, Andriessen A, Charles HE, Thompson D, Lee DT, So WK et al (2012) Randomized controlled trial comparing treatment outcome of two compression bandaging systems and standard care without compression in patients with venous leg ulcers. J Eur Acad Dermatol Venereol 26(1):102-110. https://doi.org/10.1111/j.14683083.2011.04327.x 
76. Harrison MB, VanDenKerkhof EG, Hopman WM, Graham ID, Carley ME, Nelson EA (2011) The Canadian Bandaging Trial: evidence-informed leg ulcer care and the effectiveness of two compression technologies. BMC Nurs 10(1):20. https://doi.org/10. 1186/1472-6955-10-20

77. O'Meara S, Cullum N, Nelson EA, Dumville JC (2012) Compression for venous leg ulcers. Cochrane Database Syst Rev 11:CD000265

78. Vanscheidt W, Ukat A, Partsch H (2009) Dose-response of compression therapy for chronic venous edema-higher pressures are associated with greater volume reduction: two randomized clinical studies. J Vasc Surg 49(2):395-402

79. Harlander-Locke M, Lawrence PF, Alktaifi A, Jimenez JC, Rigberg D, DeRubertis B (2012) The impact of ablation of incompetent superficial and perforator veins on ulcer healing rates. J Vasc Surg 55(2):458-464. https://doi.org/10.1016/j.jvs.2011.08.054

80. Harlander-Locke M, Lawrence P, Jimenez JC, Rigberg D, DeRubertis B, Gelabert H (2012) Combined treatment with compression therapy and ablation of incompetent superficial and perforating veins reduces ulcer recurrence in patients with CEAP 5 venous disease. J Vasc Surg 55(2):446-450. https://doi.org/10. 1016/j.jvs.2011.08.009

81. Darvall KA, Bate GR, Adam DJ, Silverman SH, Bradbury AW (2009) Ultrasound-guided foam sclerotherapy for the treatment of chronic venous ulceration: a preliminary study. Eur J Vasc Endovasc Surg 38(6):764-769. https://doi.org/10.1016/j.ejvs. 2009.05.027

82. Alden PB, Lips EM, Zimmerman KP, Garberich RF, Rizvi AZ, Tretinyak AS, Alexander JQ, Dorr KM, Hutchinson M, Isakson SL (2013) Chronic venous ulcer: minimally invasive treatment of superficial axial and perforator vein reflux speeds healing and reduces recurrence. Ann Vasc Surg 27(1):75-83. https://doi.org/10. 1016/j.avsg.2012.06.002

83. Samuel N, Carradice D, Wallace T, Smith GE, Chetter IC. Endovenous thermal ablation for healing venous ulcers and preventing recurrence. Cochrane Database Syst Rev (10): CD009494

84. Kulkarni SR, Slim FJ, Emerson LG, Davies C, Bulbulia RA, Whyman MR et al (2013) Effect of foam sclerotherapy on healing and long-term recurrence in chronic venous leg ulcers. Phlebology 28(3):140-146. https://doi.org/10.1258/phleb.2011.011118

85. Grover G, Tanase A, Elstone A, Ashley S (2016) Chronic venous leg ulcers: effects of foam sclerotherapy on healing and recurrence. Phlebology 31(1):34-41. https://doi.org/10.1177/ 0268355514557854

86. Van Gent WB, Catarinella FS, Lam YL, Nieman FH, Toonder IM, van der Ham AC et al (2015) Conservative versus surgical treatment of venous leg ulcers: 10-year follow up of a randomized, multicenter trial. Phlebology 30(1_suppl):35-41. https://doi.org/ $10.1177 / 0268355514568848$

87. Howard DP, Howard A, Kothari A, Wales L, Guest M, Davies AH (2008) The role of superficial venous surgery in the management of venous ulcers: a systematic review. Eur J Vasc Endovasc Surg 36(4):458-465. https://doi.org/10.1016/j.ejvs.2008.06.013

88. Wright DD (2009) The ESCHAR trial: should it change practice? Perspect Vasc Surg Endovasc Ther 21(2):69-72. https://doi.org/10. $1177 / 1531003509337156$

89. Nelson EA, Bell-Syer SE (2014) Compression for preventing recurrence of venous ulcers. Cochrane Database Syst Rev 9: CD002303 